ORIGINAL ARTICLE

\title{
Risk of upper aerodigestive tract cancers in a case-cohort study of autoworkers exposed to metalworking fluids
}

\author{
A Zeka, E A Eisen, D Kriebel, R Gore, D H Wegman
}

Occup Environ Med 2004;61:426-431. doi: 10.1136/oem.2003.010157

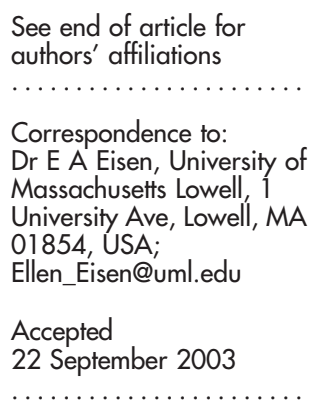

\begin{abstract}
Aims: To re-examine aerodigestive cancer risk in a cohort of autoworkers exposed to metal working fluids (MWF), using improved case definition and more recently diagnosed cases.

Methods: The autoworker cohort included 31100 hourly workers alive on 1 January 1985 who worked at three automobile plants in Michigan. A case-cohort design was carried out that included incident cases of cancers of the larynx, oesophagus, and stomach, and a 10\% sample of the cohort. A Cox proportional hazards model was used to estimate MWF exposure effects. The smoothing method of penalised splines was used to explore the shape of the underlying exposure-response curves.

Results: The most important finding was the association between larynx cancer incidence and cumulative straight MWF exposure. The results for oesophageal cancer were less consistent. For stomach cancer there was no evidence of excess risk.

Conclusion: This association between larynx cancer and straight MWF exposures was consistent with a previous finding in this cohort, providing further support for a causal relation.
\end{abstract}

pr ncreased risks of aerodigestive tract cancers have been previously observed in workers exposed to metal working fluids (MWF). Substantial evidence has been found for the MWF related risk of cancers of the larynx, rectum, and pancreas; and less consistently for cancers of oesophagus and stomach. ${ }^{1}$ Much of the evidence comes from studies nested in a large cohort of automotive manufacturing workers (General Motors/United Autoworkers, GM/UAW) exposed to MWF followed up from 1941 to 1994. In initial standardised mortality ratio (SMR) analyses of this cohort (followed until 1985), there was excess mortality risk for laryngeal, oesophageal, and stomach cancer among autoworkers exposed to MWF. ${ }^{2}$ In a second report of the cohort, Tolbert and colleagues ${ }^{3}$ measured duration of exposure to specific types of fluid and found some suggestion of modest associations for several cancer endpoints, including laryngeal, oesophageal, stomach, and rectal cancer mortality and exposures to straight and soluble MWF types. ${ }^{3}$ These findings were pursued further in a series of case-control studies nested in the cohort. ${ }^{4-7}$ In the only previous study of incident cases, a twofold increase in risk of laryngeal cancer was found for the highest category of straight fluid exposures (greater than $0.5 \mathrm{mg} / \mathrm{m}^{3}$-years). ${ }^{4}$ In a latter study by Sullivan and colleagues, ${ }^{5}$ an increased risk of oesophageal cancer mortality was associated with any exposure to synthetic MWF, and a ninefold relative risk was found among those with more than 12 years' of work in grinding operations using soluble MWF. ${ }^{5}$ A case-control study of stomach cancer was inconclusive. ${ }^{6}$ Eisen and colleagues recently extended follow up for an additional 10 years, through $1994 .{ }^{7}$ Increased risks for oesophageal and laryngeal cancer mortality were found with both straight and soluble MWF. Synthetic MWF were found associated with oesophageal cancer mortality. ${ }^{7}$

The present study was carried out to re-examine the aerodigestive cancer risk in association with MWF in the GM/ UAW cohort. Approximately 1.2 million workers are exposed to MWF in the USA. ${ }^{8}$ MWF are used in metalworking operations, to cool, lubricate, prevent rust, and carry away metal chips. They can be classified into three main types: straight, soluble, and synthetic fluids. Straight fluids are naphthenic or paraffinic mineral and fatty oils containing polycyclic aromatic hydrocarbons and extreme pressure additives such as compounds of chlorine, sulphur, or phosphorus. Soluble fluids are paraffinic or naphthenic mineral or fatty oils emulsified in water, and may contain alkanolamines to buffer $\mathrm{pH}$, nitrites added to inhibit corrosion, and biocides. Synthetic fluids consist of organic chemicals dissolved in water, ethanolamines as a corrosion inhibitor or $\mathrm{pH}$ buffer, and biocides. MWF are used in two main operations: machining and grinding. These operations differ with respect to the particle sizes created during the processes, and also in the chemical composition of the aerosols generated.

The present study extended previous studies of aerodigestive cancers and MWF in the GM/UAW from 1985 to 2000, by identifying new incident cases of aerodigestive cancers for these additional follow up years: cancers of the larynx, oesophagus, and stomach. In this study we refined the definitions of oesophageal and stomach cancer to include histology and morphology, in addition to the anatomic definition. There are two major types of oesophageal cancers: adenocarcinoma (ADC) and squamous cell carcinoma (SCC). Adenocarcinomas of the oesophagus, together with those arising from the gastric cardia junction are considered as one entity; histologically and morphologically different from adenocarcinoma of the stomach. ${ }^{9}$ Studies have also shown aetiological differences between adenocarcinomas of the stomach on the one hand, and adenocarcinomas of the oesophagus and cardia junction on the other. ${ }^{10-14}$ The latter have been increasing rapidly in recent decades, while the former have been decreasing in incidence in many western countries. ${ }^{14}{ }^{15}$ In these analyses, we distinguished between ADC of the oesophagus and cardia junction, SCC of the oesophagus, ADC of the stomach (simply "stomach carcinoma"), and laryngeal cancer-mainly SCC.

Another refinement of this analysis over previous studies of MWF and aerodigestive cancers was the investigation of

\footnotetext{
Abbreviations: ADC, adenocarcinoma; GM/UAW, General Motors/ United Autoworkers; ICD-O, International Classification of DiseasesOncology; MWF, metal working fluids; NDI, National Death Index; OR, odds ratio; RR, rate ratio; SCC, squamous cell carcinoma; SMR, standardised mortality ratio
} 
Main message

- MWF were shown to increase risk of laryngeal cancer, and there was some suggestion that they may increase risk of other aerodigestive tract cancers.

hypotheses about temporal carcinogenic effects of MWF exposures using time windows of cumulative exposure. Finally, a case-cohort analysis was used for the present study, so that incidence rate ratios could be estimated directly, rather than approximated by odds ratios as in a nested case-control study.

\section{METHODS}

The GM/UAW cohort of automotive workers included 46400 hourly workers at three automobile plants in Michigan. All hourly employees who had worked at least three years between 1 January 1938 and 1 January 1985 were eligible for the study. Follow up started in 1941 and ended in 1994. For this study, we identified 31100 subjects in the cohort alive on 1 January 1985.

\section{Cases}

We requested the Michigan Cancer Registry to identify all incident cases of aerodigestive cancers that had occurred in the cohort from 1 January 1985 (the date the Michigan Cancer Registry began) through 1 January 2000, for the following sites: oropharyngeal cancer (ICD-O code 10th revision; C10.0C10.9), hypopharyngeal cancer (C13.0-C13.9), laryngeal cancer (C32.0-C32.9), oesophageal cancer (C15.0-C15.9), and stomach cancer (C16.0-C16.9). We considered four distinguishable histological and morphological sites: laryngeal cancer (mainly SCC), including all incident cancers of larynx; oesophageal SCC, excluding morphology type 8140/ and 8144/ for ICD-O C15.0C15.9; adenocarcinoma of oesophagus and cardia junction, including morphology codes 8140/ and 8144/ of ICD-O C15.0-C15.9 (oesophagus), and 8140/ and 8144/ of ICD-O C16.0 (cardia junction); and carcinoma of the stomach, excluding morphology code 8140/ and 8144/ of C16.0 (cardia junction). The five digit morphology code was available for incident cases. In this cohort, there were only two pharyngeal cancer cases (oropharyngeal and hypopharyngeal cancers together), and so this site was not used in the present analyses. Unfortunately, it was not possible to include women in the study, because there were only 13 female aerodigestive cancer cases, including 10 cases of stomach cancer, two cases of laryngeal cancer, and one case of oesophageal cancer.

\section{Subcohort}

A subcohort of 3110 males was selected as the referent group in the case-cohort analyses using a 10\% random sampling of the whole MWF male cohort alive on 1 January 1985.

The eligible subcohort members were either still at work, had left work and were verified to be alive (by the National Death Index (NDI) and Social Security Administration), or, in a small number of cases, were of unknown vital status (and assumed to be alive on 1 January 1985). Those subjects who were born before 1900 with vital status "unknown" were excluded from the selection (17 subjects). The remaining 3093 subcohort members were examined for vital status as of 31 December 1994. Of these, 915 subjects were determined to be "at work" and "alive" at the end of this follow up period. During the 10 year period 1985-94, 495 subjects had died. For the remaining 1683 subjects with vital status uncertain, we carried out an NDI update, in summer 2001, extending the follow up period to 31 December 1999.
Policy implication

- At the current $\mathrm{NIOSH}$ recommended standard of $0.5 \mathrm{mg} / \mathrm{m}^{3}$, the observed $8 \%$ excess risk of laryngeal cancer per $5 \mathrm{mg} / \mathrm{m}^{3}$-years of cumulative straight MWF would be attained after 10 years of exposure. Continuing to lower levels of MWF will contribute to reduce risk of cancer in exposed worker populations.

For those subjects not identified as deceased through this search, we calculated their age on 31 December 1999 and censored subjects at their 85 th birthday if this was between 1 January 1995 and 31 December 1999. Otherwise, subjects were assumed alive.

\section{Exposure assessment}

Exposure histories were available for the cohort until the end of follow up in 1994. After 1994, in the absence of work records, a cut-off at 60 years of age was considered as the retirement age, based on the mean age of termination of work in the subcohort. For subjects alive during any of the five additional years of follow up, we terminated their work history at their 60th birthday, if this was before 31 December 1999. Otherwise, their last day at work was assumed to be at the end of follow up. For active workers the average annual exposures in 1994 were assigned to each additional year at work.

Three automobile part manufacturing facilities were selected on the basis of the number of workers ever worked at the plant and the types of fluids used over time. Plant 1 manufactured steering gears, plant 2 automotive transmissions, and plant 3 manufactured axles and drive train gears. For exposures concurrent with the original definition of the GM/UAW cohort in 1985, information was collected from company lists and verified by exposure assessment surveys. Personal and general area measurements were carried out during $1980-87$ by a research team, which visited all three plants. ${ }^{16}{ }^{17}$ On the basis of plant records, existing industrial hygiene data, and a field survey, fluid type and air concentrations were assigned to each department and job in each plant. All plants were revisited by one of the original industrial hygienists to update exposures in 1994.

For this study we excluded subjects missing more than $50 \%$ of their work history. The MWF total aerosol concentrations assigned to each job and department were combined with work histories to estimate annual exposures and then cumulated to estimate cumulative exposures for each of the three metal working fluid types: soluble, synthetic, and straight. Cumulative exposures were also estimated separately for each fluid type by type of operation, in grinding and machining. Time windows of cumulative exposure were constructed for each of the fluid types: the most recent 10 years, 10 to 20 years, and 20 or more years prior to the risk age. Effect estimates were expressed on the relative increase in risk (RR) for an increase in cumulative exposure of $5 \mathrm{mg}$ / $\mathrm{m}^{3}$-years-a value that was not unusual in this cohort.

\section{Statistical methods of analysis}

A case-cohort design was used rather than a nested casecontrol study, so that cancer incidence rates for the aerodigestive tract cancers could be estimated directly. A random sample of the whole cohort was selected as the comparison group ("subcohort") with sampling probability $\propto(0.10$ in this case), without regard to case status or time. A Cox proportional hazards model was used for analyses, as if the full cohort were included, modified by a weighting scheme 
described by Barlow and colleagues. ${ }^{18}$ We used a robust variance estimate, also described by Barlow ${ }^{18}{ }^{19}$ and Lin and Wei. ${ }^{20}$ In the case-cohort design, weights are assigned to each subject, one for cases, and $1 / \alpha$ (10 in this case) for the subcohort members.

Age at diagnosis $(t)$ of a case (risk age) defined a risk set. The subcohort members were used repeatedly, as in the standard Cox regression, in every risk set for which they qualified, if their age at the end of follow up was equal to or greater than risk age. This means that exposures for the subcohort were recalculated for each risk set in which they appeared. A case was not considered "at risk" until just before its failure time. Each subcohort member was eligible for the risk set only if they had reached the risk age after 1 January 1985 and before the end of follow up.

\section{Cox proportional hazards with penalised splines}

To validate the linearity assumption built into the Cox model regarding the shape of the exposure-response curve, penalised splines were used to allow more flexibility by modelling the log hazard ratio as a smooth function of exposure. This smoothing method makes no assumptions regarding the shape of the association, therefore allows for non-linearities to be estimated. ${ }^{21} 22$ The coding for the non-parametric casecohort analyses was based on the work of Therneau and $\mathrm{Li}^{23}$ and Mark and Katki. ${ }^{24}$ The shape (how smooth or "jagged") of the exposure-risk curve from spline methods depends largely on the amount of smoothing applied. The optimal degree of smoothing was chosen based in part on Akaike's information criterion as a measure of goodness of fit.

Correlations among fluid types were examined, and found to be fairly low; so that there was little risk of serious collinearity in models including several different fluid types. Exposures were used in separate models and also adjusted for each other (three fluid types). To control for any confounding of exposure in one time window by exposures in other time windows, all three windows of cumulative exposure for each fluid type were adjusted for each other in the models. ${ }^{25}$ We also adjusted for important covariates: plant, race, birth cohort, year started work, and year entered the cohort.

\section{RESULTS}

The following incident cases of aerodigestive cancers were identified: 78 laryngeal cancer, 77 stomach carcinomas, 37 cases of oesophageal SCC, and 36 cases of adenocarcinoma of oesophagus and oesophageal-cardia junction. A total of 3093 subcohort members were identified, 140 of whom were excluded because they were missing more than $50 \%$ of their work history. None of the cases were excluded for this reason.

Table 1 summarises the characteristics of the subcohort and the four groups of cases. Most of the subcohort members were white, as were most cases, except for SCC of oesophagus, where whites and blacks appeared with comparable frequencies. The distributions of cases among the three plants did not differ much from the subcohort. Subcohort members entered the cohort and started work, on average, 67 years later than the cases (table 1).

Table 2 shows exposure distributions for all groups. In Cox regression, each subcohort member appears multiple times with different cumulative exposures associated with each different risk set. Here, for simplicity, we have presented their cumulative exposures to the end of follow up (table 2). Among all groups, soluble fluids were the most prevalent, ranging from $83 \%$ to $97 \%$. Straight MWF exposures occurred in about $60 \%$ of cases, and in about $58 \%$ of the subcohort. The least common fluid type was synthetic with $20-30 \%$ among cases, and 35\% among the subcohort. Soluble fluids were used with almost equal frequency in grinding and machining operations, while straight fluids were used predominantly in machining, and synthetics predominantly in high speed grinding. Comparing exposures among all groups, the average exposure to straight fluids was higher and more variable for larynx cancer cases than in all other cancer types, as well as for the subcohort. Correlations among fluid types were all close to zero (data not shown).

Positive associations were observed between aerodigestive cancers at several sites and different MWF types (table 3). The strongest association was between laryngeal cancer and straight fluid exposure, which showed a $7 \%$ increase in risk for each $5 \mathrm{mg} / \mathrm{m}^{3}$-year increment in cumulative exposure $(\mathrm{RR}=1.07 ; 95 \% \mathrm{CI} 1.01$ to 1.12$)$. This association was observed in the 10 to 20 years window prior to risk date $(\mathrm{RR}=1.42 ; 95 \% \mathrm{CI} 0.97$ to 2.07$)$, and to a lesser degree in the $20+$ years window $(\mathrm{RR}=1.06 ; 95 \% \mathrm{CI} 0.99$ to 1.13$)$. Straight MWF exposure in these two windows combined was associated with an $8 \%$ excess risk per $5 \mathrm{mg} / \mathrm{m}^{3}$-years $(95 \%$ CI 1.03 to 1.14). No other fluid types were associated with laryngeal cancer risk.

There was little evidence that stomach carcinoma was associated with any fluid type (table 3). The strongest association in our study was observed for the recent 10 years of cumulative exposures to soluble fluids ( $\mathrm{RR}=1.29 ; 95 \% \mathrm{CI}$ 0.63 to 2.67 ).

Oesophageal SCC was also only weakly associated with any MWF. There was a positive association with cumulative exposure to soluble fluids in the most recent 10 years $(\mathrm{RR}=1.42$; $95 \%$ CI 0.65 to 3.11 ), and with cumulative exposure to synthetic fluids $20+$ years prior to risk age $(\mathrm{RR}=1.39$; $95 \% \mathrm{CI}$ 0.85 to 2.28 ), although both confidence intervals were wide. Because of prior evidence on oesophageal cancer mortality, we also examined risk associated with grinding, without regard to fluid type, and found increased risk in the 10 years just prior to risk age $(\mathrm{RR}=2.15 ; 95 \% \mathrm{CI} 0.70$ to 6.58$)$ (table 3). Grinding with soluble MWF was also associated with an increased risk for the first window with a similarly wide confidence interval ( $\mathrm{RR}=1.94 ; 95 \% \mathrm{CI} 0.67$ to 5.67 ).

A small excess risk was found for adenocarcinoma of oesophagus and cardia junction with exposures to soluble MWF $(\mathrm{RR}=1.03 ; 95 \%$ CI 0.96 to 1.11$)$, and straight MWF $(\mathrm{RR}=1.06 ; 95 \% \mathrm{CI} 0.93$ to 1.21$)$, in the $20+$ years window (table 3$)$. When the exposure definition was refined to include only soluble MWF during machining operations, the association was somewhat stronger $(\mathrm{RR}=1.12 ; 95 \% \mathrm{CI} 0.97$ to 1.29$)$.

All models were controlled for potential confounding: race, plant, birth cohort, year started work, and year entered the cohort. None of these factors changed the exposure effect estimates and so are not discussed further.

\section{Smoothing}

A Cox model with penalized splines was also applied to smooth the exposure-response relation for several of the important associations (table 3). However, we present only the curve for larynx cancer and the 10+ years' window of cumulative straight MWF (fig 1). The relative risk increased linearly with increasing cumulative exposure, and the smoothed confidence interval appeared to be fairly tight around the exposure function. A relative risk of around 3.0 $(\ln (R R)=1.1)$ was observed at a cumulative exposure history of $75 \mathrm{mg} / \mathrm{m}^{3}$-years, which was approximately the 99th centile of the case exposure distribution.

\section{DISCUSSION}

We used a case-cohort design to estimate incidence rate ratios for associations between aerodigestive cancers and MWF exposures, among cases diagnosed after l January 1985. Unfortunately females were excluded from the analyses 
Table 1 Demographic characteristics of GM/UAW male auto-workers in a nested case-cohort study of aerodigestive tract cancers

\begin{tabular}{|c|c|c|c|c|c|}
\hline & Subcohort & Larynx & Stomach & Oesophageal SCC & $\begin{array}{l}\text { Oesophageal and cardio } \\
\text { junction ADC } \dagger\end{array}$ \\
\hline Number (\%) & $3093(100)$ & $78(100)$ & $77(100)$ & $37(100)$ & $36(100)$ \\
\hline \multicolumn{6}{|l|}{ Race } \\
\hline White & $2064(66.7)$ & $42(53.9)$ & 48 (62.3) & $17(46.0)$ & $22(61.1)$ \\
\hline Black & $517(16.7)$ & $20(25.6)$ & $20(26.0)$ & $15(40.5)$ & $0(0)$ \\
\hline Unknown & $512(16.6)$ & $16(20.5)$ & $9(11.7)$ & 5 (13.5) & $14(38.9)$ \\
\hline \multicolumn{6}{|l|}{ Plant } \\
\hline Plant 1 & $861(27.8)$ & $32(41.0)$ & $32(41.6)$ & $19(51.4)$ & $9(25.0)$ \\
\hline Plant 2 & $1164(37.6)$ & $26(33.3)$ & $27(35.1)$ & $11(29.7)$ & $15(41.7)$ \\
\hline Plant 3 & 1068 (34.5) & $20(25.6)$ & $18(23.4)$ & 7 (18.9) & $12(33.3)$ \\
\hline \multicolumn{6}{|c|}{$\begin{array}{l}\text { Vital status on } 31 \text { December } \\
1999\end{array}$} \\
\hline $\begin{array}{l}1999 \\
\text { Alive }\end{array}$ & 2206 (71.3) & $54(69.2)$ & $37(48.1)$ & $15(40.5)$ & $17(47.2)$ \\
\hline Dead & 752 (24.3) & $22(28.2)$ & 38 (49.4) & $21(56.8)$ & 17 (47.2) \\
\hline Unknown & $135(4.4)$ & $2(2.6)$ & $2(2.6)$ & $1(2.7)$ & $2(5.6)$ \\
\hline \multicolumn{6}{|c|}{ Year started workł } \\
\hline Mean & 1963 & 1956 & 1956 & 1957 & 1957 \\
\hline Range & $1921-81$ & 1933-79 & $1927-79$ & $1930-77$ & $1934-76$ \\
\hline \multicolumn{6}{|c|}{ Year entered cohort } \\
\hline Mean & 1966 & 1960 & 1959 & 1961 & 1960 \\
\hline Range & $1941-84$ & $1941-82$ & $1941-82$ & $1941-80$ & $1941-79$ \\
\hline \multicolumn{6}{|l|}{ Year of birth } \\
\hline Mean & 1937 & 1929 & 1927 & 1927 & 1930 \\
\hline Range & $1892-61$ & $1905-57$ & $1903-57$ & $1909-50$ & $1910-57$ \\
\hline \multicolumn{6}{|c|}{ Age at diagnosis } \\
\hline Mean (SD) & - & $63.5(10.3)$ & $66.0(13.1)$ & $65.6(10.3)$ & $63.4(9.9)$ \\
\hline
\end{tabular}

Aerodigestive incident cancers and a 10\% random sample of the cohort alive on 1 January 1985.

*SCC, squamous cell carcinoma.

†ADC, adenocarcinoma.

$\ddagger$ Calendar year of hire +3 years.

due to small numbers. From a total of 243 aerodigestive cancers, only 13 were females ( $5 \%$ of all aerodigestive cancer cases), which was disproportionately low compared to the $10 \%$ female composition of the GM/UAW cohort. One concern in incidence studies is case loss due to migration. Since all of our analyses were based on internal comparisons, however, case loss would not affect our risk estimates.

\section{Laryngeal cancer}

The strongest association in this study was found for laryngeal cancer and straight MWF exposure. This finding generally supported previous results from the same cohort reported by Eisen and colleagues, ${ }^{4}$ based on slightly overlapping case groups (26 incident cases of laryngeal cancer in both studies). The strongest effect in our study was from exposures occurring 10 to 20 years prior to risk age, and to a lesser degree $20+$ years' prior to risk age. Combining these two windows resulted in an excess risk of $8 \%$ per $5 \mathrm{mg} /$ $\mathrm{m}^{3}$-years' increment of cumulative straight MWF exposure. The result from Cox regression with penalised splines (fig l) has shown that risk continues to rise linearly with increasing exposure. The previous case-control study ${ }^{4}$ which included incident cases of larynx cancer together with mortality cases, reported results using both continuous and categorical exposure variables. In a continuous exposure model, the previous study reported a $6 \%$ excess risk of laryngeal cancer

Table 2 Cumulative MWF exposures (in $\mathrm{mg} / \mathrm{m}^{3}$-years) for aerodigestive cancer cases and subcohort of the GM/UAW cohort alive on 1 January 1985: total time and windows of time*

\begin{tabular}{|c|c|c|c|c|c|}
\hline MWF types & $\begin{array}{l}\text { Subcohort } \\
\text { Mean (SD) }\end{array}$ & $\begin{array}{l}\text { Larynx } \\
\text { Mean (SD) }\end{array}$ & $\begin{array}{l}\text { Stomach } \\
\text { Mean (SD) }\end{array}$ & $\begin{array}{l}\text { Oesophageal SCC } † \\
\text { Mean (SD) }\end{array}$ & $\begin{array}{l}\text { Oesophageal and cardia } \\
\text { junction ADC } \\
\text { Mean (SD) }\end{array}$ \\
\hline \multicolumn{6}{|l|}{ Soluble } \\
\hline All time & $11.08(19.24)$ & $12.19(19.75)$ & $16.07(23.38)$ & 11.35 (14.71) & $15.93(25.62)$ \\
\hline Recent 10 years window & $0.30(0.75)$ & $0.61(1.38)$ & $0.64(1.33)$ & $0.79(2.08)$ & $0.51(1.11)$ \\
\hline 10 to 20 years window & $1.28(2.47)$ & $1.60(2.68)$ & $2.01(3.91)$ & $1.89(3.95)$ & $1.91(2.95)$ \\
\hline 20 or more years window & $9.50(18.71)$ & $9.99(18.65)$ & $13.42(21.34)$ & $8.67(12.20)$ & $13.52(23.28)$ \\
\hline \multicolumn{6}{|l|}{ Straight } \\
\hline All time & $2.56(9.71)$ & $6.84(23.37)$ & $2.62(6.72)$ & $2.33(5.94)$ & $3.63(8.54)$ \\
\hline Recent 10 years window & $0.05(0.38)$ & $0.10(0.41)$ & $0.14(0.57)$ & $0.14(0.46)$ & $0.16(0.80)$ \\
\hline 10 to 20 years window & $0.33(1.38)$ & $1.01(3.37)$ & $0.42(1.45)$ & $0.22(0.95)$ & $0.28(0.66)$ \\
\hline 20 or more years window & $2.18(9.25)$ & $5.70(21.65)$ & $2.06(5.71)$ & $1.97(5.93)$ & $3.19(8.39)$ \\
\hline \multicolumn{6}{|l|}{ Synthetic } \\
\hline All time & $0.61(2.64)$ & $0.91(4.94)$ & $0.45(1.57)$ & $0.82(2.40)$ & $0.62(2.69)$ \\
\hline Recent 10 years window & $0.04(0.25)$ & $0.03(0.09)$ & $0.06(0.37)$ & $0.02(0.11)$ & $0.02(0.07)$ \\
\hline 10 to 20 years window & $0.14(0.60)$ & $0.16(0.72)$ & $0.07(0.33)$ & $0.03(0.11)$ & $0.12(0.42)$ \\
\hline 20 or more years window & $0.43(2.40)$ & $0.72(4.22)$ & $0.31(1.36)$ & $0.77(2.32)$ & $0.48(2.28)$ \\
\hline
\end{tabular}

*Cumulative exposures calculated for cases at the age of diagnosis, and for subcohort at the end of follow up.

†SCC, squamous cell carcinoma.

$\ddagger A D C$, adenocarcinoma. 
Table 3 Cox proportional hazards regression results (rate ratios) by cancer site, MWF type, and time window

\begin{tabular}{|c|c|c|c|c|c|c|c|c|}
\hline \multirow[b]{2}{*}{ Cancer site } & \multicolumn{2}{|c|}{ Total time } & \multicolumn{2}{|c|}{ Recent 10 years* } & \multicolumn{2}{|c|}{$10-20$ years } & \multicolumn{2}{|c|}{$20+$ years } \\
\hline & RR† & $95 \% \mathrm{Cl}$ & RR & $95 \% \mathrm{Cl}$ & $\mathbf{R R}$ & $95 \% \mathrm{Cl}$ & $\mathbf{R R}$ & $95 \% \mathrm{Cl}$ \\
\hline \multicolumn{9}{|c|}{ Larynx SCC ( $n=78)$} \\
\hline Soluble & 0.97 & 0.91 to 1.04 & 1.22 & 0.56 to 2.66 & 0.72 & 0.46 to 1.14 & 1.00 & 0.93 to 1.07 \\
\hline Straight & 1.07 & 1.01 to 1.12 & 0.12 & 0.01 to 1.89 & 1.42 & 0.97 to 2.07 & 1.06 & 0.99 to 1.13 \\
\hline Synthetic & 1.03 & 0.76 to 1.39 & $-\ddagger$ & $-\ddagger$ & 1.25 & 0.30 to 5.22 & 1.09 & 0.75 to 1.56 \\
\hline \multicolumn{9}{|c|}{ Stomach carcinoma $(n=77)$} \\
\hline Soluble & 1.00 & 0.95 to 1.05 & 1.29 & 0.63 to 2.67 & 0.96 & 0.68 to 1.33 & 1.00 & 0.95 to 1.06 \\
\hline Straight & 0.96 & 0.84 to 1.08 & 1.25 & 0.19 to 8.29 & 0.94 & 0.42 to 2.08 & 0.95 & 0.82 to 1.11 \\
\hline Synthetic & 0.68 & 0.32 to 1.43 & 1.47 & 0.08 to 27.19 & 0.32 & 0.01 to 7.89 & 0.72 & 0.29 to 1.80 \\
\hline \multicolumn{9}{|c|}{ Oesophageal SCC $\S(n=37)$} \\
\hline Soluble & 0.94 & 0.84 to 1.04 & 1.42 & 0.65 to 3.11 & 0.92 & 0.54 to 1.56 & 0.92 & 0.81 to 1.06 \\
\hline Straight & 0.93 & 0.75 to 1.15 & 2.99 & 0.25 to 35.47 & 0.31 & 0.03 to 3.01 & 0.99 & 0.79 to 1.23 \\
\hline Synthetic & 0.99 & 0.60 to 1.63 & $-\ddagger$ & $-\ddagger$ & $-\ddagger$ & $-\ddagger$ & 1.39 & 0.85 to 2.28 \\
\hline Grinding & 0.96 & 0.86 to 1.07 & 2.15 & 0.70 to 6.58 & 0.79 & 0.36 to 1.74 & 0.95 & 0.82 to 1.09 \\
\hline \multicolumn{9}{|c|}{ Oesophageal and cardia junction $\mathrm{ADC}^{* *}(n=36)$} \\
\hline Soluble & 1.01 & 0.94 to 1.09 & 0.60 & 0.12 to 3.15 & 0.92 & 0.53 to 1.61 & 1.03 & 0.96 to 1.11 \\
\hline Straight & 1.01 & 0.88 to 1.15 & 2.49 & 0.24 to 25.32 & 0.34 & 0.05 to 2.40 & 1.06 & 0.93 to 1.21 \\
\hline Synthetic & $-\ddagger$ & $-\ddagger$ & $-\ddagger$ & $-\ddagger$ & 1.29 & 0.11 to 14.74 & 0.93 & 0.42 to 2.07 \\
\hline
\end{tabular}

Rate ratios presented for $5 \mathrm{mg} / \mathrm{m}^{3}$-years of cumulative exposure.

*Exposure windows prior to risk age. Windows are adjusted for each other in the models.

†Rate ratios compare $5 \mathrm{mg} / \mathrm{m}^{3}$-years of exposure to the unexposed.

†lnsufficient data.

§SCC, squamous cell carcinoma.

- Grinding, without regard to MWF type.

**ADC, adenocarcinoma.

from straight $\mathrm{MWF}(\mathrm{OR}=1.06 ; 95 \%$ CI 0.98 to 1.14 per $\mathrm{mg} / \mathrm{m}^{3}$-years $)$. A twofold increased risk (OR $=2.0 ; 95 \%$ CI 1.3 to 4.0 ) for the highest exposure category (greater than $0.5 \mathrm{mg} / \mathrm{m}^{3}$-year) was seen in a categorical exposure model. A 10 year lag of exposure was used in both models. ${ }^{4}$ A more direct comparison, however, between our findings and this previous study is difficult due to several differences in design, analysis, and presentation of results. Exposures in this earlier study $^{4}$ were estimated only for the extra-thoracic fraction

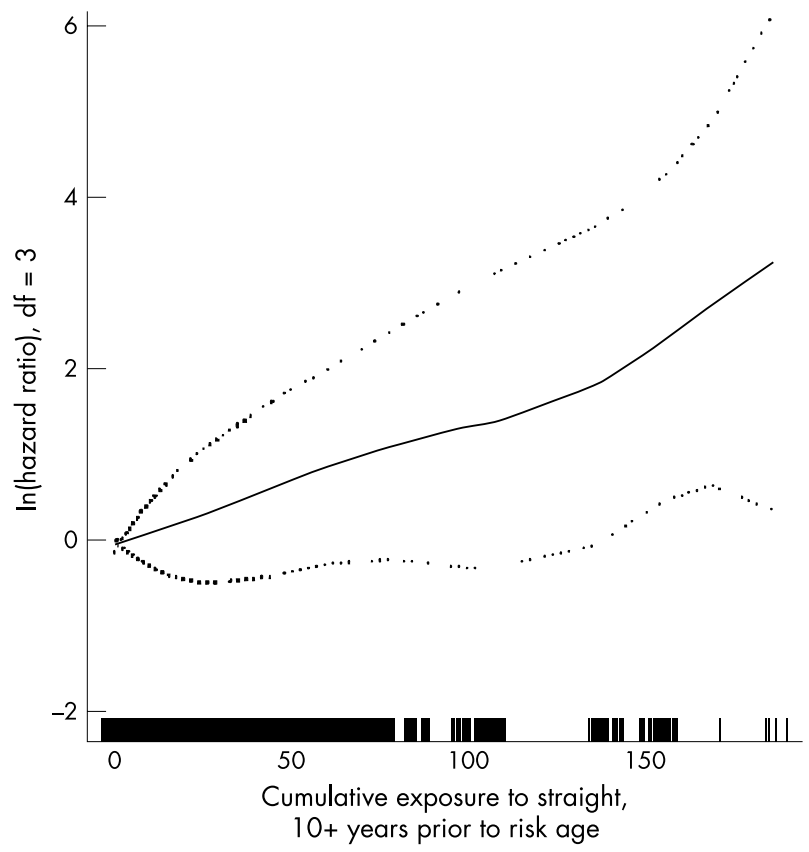

Figure 1 Risk of laryngeal cancer associated with straight MWF exposures. Cumulative exposure to straight MWF for the 10 or more years window, adjusted for the recent 10 years of cumulative straight window (exposure units in $\mathrm{mg} / \mathrm{m}^{3}$-years). (particles with a mass median diameter $>9.8 \mu \mathrm{m}$ ), which are on average $25 \%$ of the total particulate matter used in the present study.

\section{Oesophageal cancer}

There was little evidence of an increased incidence of SCC of the oesophagus from either soluble or synthetic MWF fluids. Restricting the exposure to those occurring during grinding did not appreciably alter the association (table 3 ). The confidence intervals of these associations were fairly wide, and because these were based only on 37 cases, these observations must be interpreted with caution.

\section{Adenocarcinoma of oesophagus and cardia junction}

The results for adenocarcinoma of the oesophagus and cardia junction, showed moderately increased risks for soluble and straight MWF in the earliest window of exposure. However, these results were based on only 36 cases of adenocarcinoma for the two sites together. We know of no previous studies that have examined this tumour type and MWF exposure.

A previous nested case-control analysis of this cohort found evidence of increased risk of oesophageal cancer mortality from exposures to grinding operations associated with both soluble and synthetic MWF. ${ }^{5}$ There were several methodological differences between the present study and that of Sullivan and colleagues ${ }^{5}$ that might account for the discrepancies. The previous study was a mortality rather than an incidence study; covered an earlier time period; and used a simple anatomical criterion for defining cases rather than the histological tumour classifications, used in the present study.

We investigated the effect of changing the classification from anatomic to histological by fitting additional models combining all 53 cases of oesophageal cancer (ICD-O C15.0C15.9) (16 of these were adenocarcinoma cases). There was no association between oesophageal cancer using the anatomical definition, and cumulative exposure to grinding with soluble MWF $\left(\mathrm{RR}=0.97 ; 95 \%\right.$ CI 0.87 to 1.08 per $5 \mathrm{mg} / \mathrm{m}^{3}$ years), previously shown to be associated. ${ }^{5}$ When windows of exposure were analysed, the most recent 10 years prior to risk age was the only window to show any evidence of excess risk 
$\left(\mathrm{RR}=1.86 ; 95 \% \mathrm{CI}\right.$ to 0.61 to 5.68 per $5 \mathrm{mg} / \mathrm{m}^{3}$-years $)$. We found slight increases in risk for grinding with synthetic MWF (RR $=1.05 ; 95 \%$ CI 0.75 to 1.47 ), with nearly all the effect in the $20+$ years prior to risk age time window $(\mathrm{RR}=1.68 ; 95 \%$ CI 0.51 to 5.57$)$. Confidence intervals were wide, however, leaving this question unresolved.

\section{Stomach cancer}

In the updated cohort study, Eisen and colleagues ${ }^{7}$ reported increased stomach cancer mortality in the last 10 years of follow up ( $\mathrm{SMR}=1.5 ; 95 \%$ CI 1.1 to 2.0 ), and among those hired after 1970 (SMR $=2.5 ; 95 \%$ CI 1.0 to 5.3). However, no trend in exposure-response was observed in this previous study for stomach cancer and any of the MWF types. ${ }^{7}$ Several previous mortality studies of other working populations exposed to MWF have reported excess risk of stomach cancer either for machinists as a group, ${ }^{26}{ }^{27}$ or for workers exposed to grinding with water based cutting fluids, ${ }^{28}$ or among those heavily exposed to oil mists. ${ }^{29}$ Supporting evidence was shown in a more recent study by Park, ${ }^{30}$ where increased stomach cancer mortality was associated to exposures to MWF in precision grinding $(\mathrm{OR}=2.4 ; 95 \%$ CI 1.14 to 5.10$)$.

No clear associations were found in our study for stomach carcinoma. A slight increase in risk for soluble MWF in the most recent time window was observed, but again the confidence interval was wide. As for oesophageal cancer, analyses were carried out for stomach cancer redefined anatomically, rather than histologically, which resulted in 97 cases of stomach cancer (ICD-O C16.0-C16.9) (20 of these were adenocarcinoma cases of cardia junction). Using this case definition, we found no association between stomach cancer and grinding with synthetic MWF (RR $=0.58 ; 95 \%$ CI 0.26 to 1.28 - - the fluid type with the strongest association with this cancer site in other cohorts. Furthermore, no association was found for any other MWF type alone, or by operation.

One possible explanation for the discrepancy between our findings and those of other studies is that exposures were lower for our cohort than those reported previously in this cohort. Exposures have steadily declined in the GM/UAW cohort over the past 50 years, and more radically since the mid 1980s, when additional exposure controls were implemented in this industry. ${ }^{16}$ For example, in the study of Sullivan and colleagues, ${ }^{5}$ lifetime cumulative exposures for all three MWF types (based on total particulate) reported for oesophageal cases were about twice the exposures reported for the same cancer in our study (results of Sullivan et al: mean life time exposure: soluble, $34.1 \mathrm{mg} / \mathrm{m}^{3}$-year; straight, $5.1 \mathrm{mg} / \mathrm{m}^{3}$-year; synthetic, $2.6 \mathrm{mg} / \mathrm{m}^{3}$-year). In addition, our case cohort was on average 20 years younger than the populations of the previous studies (mean year of birth for previous studies ranged between 1910 and $1917^{4}{ }^{5}$ ), which shifts this study's exposure distribution in the more recent time period.

\section{Summary}

This study showed an effect of straight MWF on laryngeal cancer, corroborating positive results in a previous casecontrol study in the same cohort. At the current NIOSH recommended standard of $0.5 \mathrm{mg} / \mathrm{m}^{3}$, the $8 \%$ excess risk per $5 \mathrm{mg} / \mathrm{m}^{3}$-years would be attained after 10 years of exposure. The lack of positive findings for the other aero-digestive cancers may be explained by the continuing decline of exposure levels over time, as well as by reduced statistical power due to the more precise case definition. The findings for adenocarcinoma of oesophagus and cardia junction bear further attention. We believe that continuing to lower levels of MWF, and eliminate additives already known to be carcinogens, ${ }^{8} 3132$ will contribute to reduce the risk of cancer in exposed worker populations.

\section{Authors' affiliations}

A Zeka, E A Eisen, D Kriebel, R Gore, D H Wegman, Work Environment Department, University of Massachusetts Lowell, Lowell, MA, USA

Supported by a grant from the US National Institute for Occupational Safety and Health, Centers for Disease Control and Prevention, R01$\mathrm{OHO} 3575$

\section{REFERENCES}

1 Calvert GM, Ward E, Schnorr TM, et al. Cancer risks among workers exposed to metalworking fluids: a systematic review. Am J Ind Med 1998;33:282-92.

2 Eisen EA, Tolbert PE, Monson RR, et al. Mortality studies of machining fluid exposure in the automobile industry. I: A standardized mortality ratio analysis. Am J Ind Med 1992;22:809-24.

3 Tolbert PE, Eisen EA, Pothier $\amalg$, et al. Mortality studies of machining-fluid exposure in the automobile industry. II. Risks associated with specific fluid types. Scand J Work Environ Health 1992;18:351-60.

4 Eisen EA, Tolbert PE, Hallock MF, et al. Mortality studies of machining fluid exposure in the automobile industry. III: A case-control study of larynx cancer Am J Ind Med 1994;26:185-202.

5 Sullivan PA, Eisen EA, Woskie SR, et al. Mortality studies of metalworking fluid exposure in the automobile industry: $\mathrm{VI}$. A case-control study of esophageal cancer. Am J Ind Med 1998;34:36-48.

6 Sullivan P, Eisen EA, Kriebel D, et al. A nested case-control study of stomach cancer mortality among automobile machinists exposed to metalworking fluids. Ann Epidemiol 2000;10:480-1.

7 Eisen EA, Bardin J, Gore R, et al. Exposure-response models based on extended follow-up of a cohort mortality study in the automobile industry. Scand J Work Environ Health 2001;27:240-9.

$8 \mathrm{NIOSH}$. Criteria for a recommended standard occupational exposure to metalworking fluids. Cincinnati, OH: CDC, NIOSH, 1998

9 WHO. International classification of diseases for oncology, 2nd edition. WHO, 1990.

10 Blot WJ, Devesa SS, Kneller RW, et al. Rising incidence of adenocarcinoma of the esophagus and gastric cardia. JAMA 1991;265:1287-9.

11 Mayer RJ. Overview: the changing nature of esophageal cancer. Chest 1993; 103(4 suppl):404S-405S.

12 Brown LM, Silverman DT, Pottern LM, et al. Adenocarcinoma of the esophagus and esophagogastric junction in white men in the United States: alcohol, tobacco, and socioeconomic factors. Cancer Causes Control 1994;5:333-40.

13 Brown LM, Swanson CA, Gridley G, et al. Adenocarcinoma of the esophagus: role of obesity and diet. J Natl Cancer Inst 1995;87:104-9.

14 Sampliner RE. Adenocarcinoma of the esophagus and gastric cardia: is there progress in the face of increasing cancer incidence? Ann Intern Med 1999; 130:67-9.

15 Devesa SS, Fraumeni JF Jr. The rising incidence of gastric cardia cancer. J Natl Cancer Inst 1999:91:747-9.

16 Hallock MF, Smith TJ, Woskie SR, et al. Estimation of historical exposures to machining fluids in the automotive industry. Am J Ind Med 1994;26:621-34.

17 Woskie SR, Smith TJ, Hallock MF, et al. Size-selective pulmonary dose indices for metal-working fluid aerosols in machining and grinding operations in the automobile manufacturing industry. Am Ind Hyg Assoc J 1994;55:20-9.

18 Barlow WE, Ichikawa L, Rosner D, et al. Analysis of case-cohort designs. J Clin Epidemiol 1999;52:1165-72.

19 Barlow WE. Robust variance estimation for the case-cohort design. Biometrics 1994:50:1064-72.

20 Lin DY, Wei U. The robust inference for the Cox proportional hazards model. J Am Stat Assoc 1989;84:1074-8.

21 Hastie TJ, Tibshirani RJ. Generalized additive models. New York: Chapman \& Hall/CRC, 1990

22 Gray RJ. Flexible methods for analyzing survival data using splines, with applications to breast cancer prognosis. J Am Stat Assoc 1992;87:942-51.

23 Therneau TM, Li H. Computing the Cox model for case cohort designs. Lifetime Data Anal 1999;5:99-112.

24 Mark SD, Katki $\mathrm{H}$. Influence function based variance estimation and missing data issues in case-cohort studies. Lifetime Data Anal 2001;7:331-44.

25 Checkoway H, Pearce NE, Crawford-Brown DJ. Research methods in occupational epidemiology. New York: Oxford University Press, 1989

26 Park RM, Wegman DH, Silverstein MA, et al. Causes of death among workers in a bearing manufacturing plant. Am J Ind Med 1988;13:569-80.

27 Park RM, Mirer FE. A survey of mortality at two automotive engine manufacturing plants. Am J Ind Med 1996;30:664-73.

28 Silverstein M, Park R, Marmor M, et al. Mortality among bearing plant workers exposed to metalworking fluids and abrasives. J Occup Med 1988;30:706-14.

29 Kazerouni N, Thomas TL, Petralia SA, et al. Mortality among workers exposed to cutting oil mist: update of previous reports. Am J Ind Med 2000;38:410-16.

30 Park RM. Mortality at an automotive engine foundry and machining complex. J Occup Environ Med 2001;43:483-93.

31 International Agency for Research on Cancer. N-nitrosodiethanolamine. In: IARC monographs on the evaluation of the carcinogenic risk of chemicals to humans, some N-nitroso compounds, Vol. 17. Lyon, France: WHO, IARC, 1978:77-82.

32 International Agency for Research on Cancer. N-nitrosodiethanolamine, Nnitrosodimethylene, $\mathrm{N}$-nitrosomorphine, $\mathrm{N}$-nitrosodibutylamine. In: IARC monographs on the evaluation of the carcinogenic risk of chemicals to humans, overall evaluation of carcinogenicity: an updating of IARC monographs, Vol. 1 to 42, Suppl. 7. Lyon, France: WHO, IARC, 1987:67-8. 